\title{
Pharmacokinetics of caffeine self- administered in overdose in a Japanese patient admitted to hospital
}

\author{
Koichiro Adachi ${ }^{1,2,3}$, Satoru Beppu², Mariko Terashima ${ }^{2}$, Toshiaki Fukuda ${ }^{3}$ Jun Tomizawa', Makiko Shimizu ${ }^{1}$ and \\ Hiroshi Yamazaki ${ }^{1 *}$ (D)
}

\begin{abstract}
Background: Caffeine $(0.1 \mathrm{~g})$ is used as a central nervous system stimulant and as a nontoxic phenotyping probe for cytochrome P450 1A2. However, an increasing number of suicide attempts by caffeine overdose have been recently reported.

Case presentation: A 25-year-old woman (body weight, $43 \mathrm{~kg}$ ) who intentionally took an overdose of $5.9 \mathrm{~g}$ caffeine as a suicide attempt was emergently admitted to Kyoto Medical Center. The plasma concentrations of caffeine and its primary metabolite, $N$-demethylated paraxanthine, in the current case were 100 and $7.3 \mu \mathrm{g} / \mathrm{mL}, 81$ and $9.9 \mu \mathrm{g} / \mathrm{mL}, 63$ and $12 \mu \mathrm{g} / \mathrm{mL}$, and 21 and $14 \mu \mathrm{g} / \mathrm{mL}$, at 12, 20, 30, and $56 \mathrm{~h}$ after oral overdose, respectively. The observed apparent terminal elimination half-life of caffeine during days 1 and 2 of hospitalization was $27 \mathrm{~h}$, which is several times longer than the reported normal value. This finding implied nonlinearity of caffeine pharmacokinetics over such a wide dose range, which could affect the accuracy of values simulated by a simplified physiologically based pharmacokinetic model founded on a normal dose of $100 \mathrm{mg}$. Low serum potassium levels (2.9 and $3.5 \mathrm{mM}$ ) on days 1 and 2 may have been caused by the caffeine overdose in the current case.

Conclusions: The patient underwent infusion with bicarbonate Ringer's solution and potassium chloride and was discharged on the third day of hospitalization despite taking a potentially lethal dose of caffeine. The virtual plasma exposures of caffeine estimated using the current simplified PBPK model were higher than the measured values. The present results based on drug monitoring data and additional pharmacokinetic predictions could serve as a useful guide in cases of caffeine overdose.
\end{abstract}

Keywords: Pharmacokinetic modeling, Overdose, Serum potassium, Paraxanthine

\section{Background}

Caffeine is a commonly used central nervous system stimulant [1]. Caffeine $(0.1 \mathrm{~g})$ is also used as a nontoxic phenotyping probe for human cytochrome P450 1A2 [2-4]. Nonetheless, a fatal caffeine overdose in a 39year-old man resulting from the self-administered

\footnotetext{
* Correspondence: hyamazak@ac.shoyaku.ac.jp

'Laboratory of Drug Metabolism and Pharmacokinetics, Showa

Pharmaceutical University, 3-3165 Higashi-tamagawa Gakuen, Machida, Tokyo 194-8543, Japan

Full list of author information is available at the end of the article
}

ingestion of approximately $12 \mathrm{~g}$ of pure caffeine anhydrous has been reported [5]. However, preemptive hemodialysis and advanced life support maneuvers, respectively, in cases of caffeine overdoses of 50 and $40 \mathrm{~g}$ in 39- and 19-year-old men, respectively, were successful $[6,7]$. Other recent suicide attempts involving caffeine overdose in which the patients' severe intoxication was successfully treated have been reported [8-10]. The monitoring of plasma concentrations of caffeine over a

C C The Author(s). 2021 Open Access This article is licensed under a Creative Commons Attribution 4.0 International License, which permits use, sharing, adaptation, distribution and reproduction in any medium or format, as long as you give appropriate credit to the original author(s) and the source, provide a link to the Creative Commons licence, and indicate if changes were made. The images or other third party material in this article are included in the article's Creative Commons licence, unless indicated otherwise in a credit line to the material. If material is not included in the article's Creative Commons licence and your intended use is not permitted by statutory regulation or exceeds the permitted use, you will need to obtain permission directly from the copyright holder. To view a copy of this licence, visit http://creativecommons.org/licenses/by/4.0/. The Creative Commons Public Domain Dedication waiver (http://creativecommons.org/publicdomain/zero/1.0/) applies to the data made available in this article, unless otherwise stated in a credit line to the data. 
wide dose range may be considered in clinical or emergency situations.

The drug monitoring of steady-state plasma concentrations of individual patients in the clinical setting can be supported by pharmacokinetic models and simulations. Established full physiologically based pharmacokinetic (PBPK) models [11, 12] can predict drug monitoring results in patients [13-15]. We developed simplified PBPK models [16] and applied them to cases of edoxaban overdose [17] and overdosed duloxetine along with other antipsychotic drugs including quetiapine and trazodone [18]. The additional practical use of such PBPK models to the routine measurements of drug concentrations in blood has been suggested for paramedical staffs in emergency clinical practice $[17,18]$.

\section{Case presentation}

Here we describe the case of a 25-year-old woman (body weight, $43 \mathrm{~kg}$ ) who intentionally took an overdose of 5.9 g caffeine (usual clinical dose, $0.2-0.9 \mathrm{~g} /$ day) as a suicide attempt and was emergently admitted to Kyoto Medical Center. The patient, who had a history of neurotic depression, may have simultaneously taken lorazepam, quetiapine, risperidone, and trazodone (dosages unknown). The clinical laboratory results for this case are shown in Table 1 . The patient gave written informed consent to take part in this study and for its publication. The Ethics Committee of Kyoto Medical Center approved this study (18-018).

On arrival, the patient's awareness level, as assessed using the Glasgow Coma Scale score, was eye 3, verbal 5 , and motor 6 (E3V5M6) with a breathing rate of 16 breaths/min, a body temperature of $36.6^{\circ} \mathrm{C}$, a blood pressure of $113 / 72 \mathrm{mmHg}$, a heart rate of $83 \mathrm{bpm}$, and a QT prolongation on electro-cardiogram with a QTc of $491 \mathrm{~ms}$. Laboratory data showed hypokalemia, hyperglycemia, and hyperlacticacidemia. The patient was infused with bicarbonate Ringer's solution and potassium chloride, but was not administered activated charcoal and did not undergo artificial dialysis. By $24 \mathrm{~h}$ after admission, the patient's awareness level had improved to E4V5M6 with a reduced QTc of $<430 \mathrm{~ms}$. The patient refused endoscopic examination for suspected esophageal ulcer as a result of caffeine intake; consequently, lansoprazole was administered. The patient was discharged on the third day of hospitalization after abnormal vital signs had normalized.

We measured the plasma concentrations of caffeine and its primary metabolite paraxanthine along with the other medicines and also generated PBPK-modeled concentration profiles of caffeine and its metabolite for the current patient after a self-administered single oral caffeine overdose $(5.9 \mathrm{~g})$; the results are shown in Fig. 1. Frozen plasma samples collected from the patient after the overdose were pharmacokinetically analyzed. After deproteinization with three volumes of methanol, the plasma concentrations of caffeine and paraxanthine were quantified by liquid chromatography using a gradient elution program followed by tandem mass spectrometry [18] according to the previously described methods [2] with slight modifications. An API4000 tandem mass analyzer (AB Sciex, Framingham, MA, USA) was used in electrospray positive ionization mode and was directly coupled to a Shimadzu LC-20 AD system equipped with an octadecylsilane $\left(\mathrm{C}_{18}\right)$ column (XBridge, $3.5 \mu \mathrm{m}, 2.1$ $\mathrm{mm} \times 150 \mathrm{~mm}$, Waters, Milford, MA, USA). The liquid chromatography conditions for caffeine and paraxanthine were as follows: solvent $\mathrm{A}$ was $0.1 \%$ formic acid in water, and solvent $\mathrm{B}$ was $0.1 \%$ formic acid in methanol. The following gradient program was used at a flow rate of $0.20 \mathrm{~mL} / \mathrm{min}: 0-1 \mathrm{~min}$, hold at $5 \% \mathrm{~B} ; 1.1-17 \mathrm{~min}$, linear gradient from $5 \%$ B to $100 \%$ B (v/v); $17.1-21 \mathrm{~min}$, hold at $100 \% \mathrm{~B}$; and $21.1-24 \mathrm{~min}$, hold at $5 \% \mathrm{~B}$. The temperature of the column was maintained at $40{ }^{\circ} \mathrm{C}$. Prepared samples $(2.0 \mu \mathrm{L})$ were injected with an autosampler. Caffeine and paraxanthine were quantified using the $m / z \quad 195 \rightarrow 138$ and $181 \rightarrow 124$ transitions, respectively, with ${ }^{13} \mathrm{C}$-caffeine as an internal standard $(\mathrm{m} / z$ $198 \rightarrow 140$ ). Under these conditions, caffeine and paraxanthine levels in plasma were measurable at

Table 1 Clinical laboratory results for a patient who had taken a single oral overdose of $5900 \mathrm{mg}$ caffeine

\begin{tabular}{llll}
\hline & Day $\mathbf{1}$ at $\mathbf{1 2} \mathbf{h}$ & Day $\mathbf{2}$ at $\mathbf{3 0} \mathbf{~}$ & Day $\mathbf{3}$ at $\mathbf{5 6} \mathbf{~}$ \\
\hline Aspartate aminotransferase $(\mathrm{U} / \mathrm{L})$ & 19 & 19 & 17 \\
Alanine aminotransferase $(\mathrm{U} / \mathrm{L})$ & 11 & 11 & 15 \\
Serum creatinine $(\mathrm{mg} / \mathrm{dL})$ & 0.50 & 0.57 & 0.69 \\
Creatinine clearance $(\mathrm{mL} / \mathrm{min})$ & 117 & 102 & 85 \\
Serum potassium $(\mathrm{mmol} / \mathrm{L})$ & 2.9 & 3.5 & 3.7 \\
Serum sodium $(\mathrm{mmol} / \mathrm{L})$ & 137 & 139 & 141 \\
Serum glucose $(\mathrm{mg} / \mathrm{dL})$ & 190 & 126 & 87 \\
pH [venous blood gas] & 7.43 & 7.43 & not available \\
Lactic acid [venous blood gas] (mmol/L) & 3.01 & 0.96 & not available \\
\hline
\end{tabular}




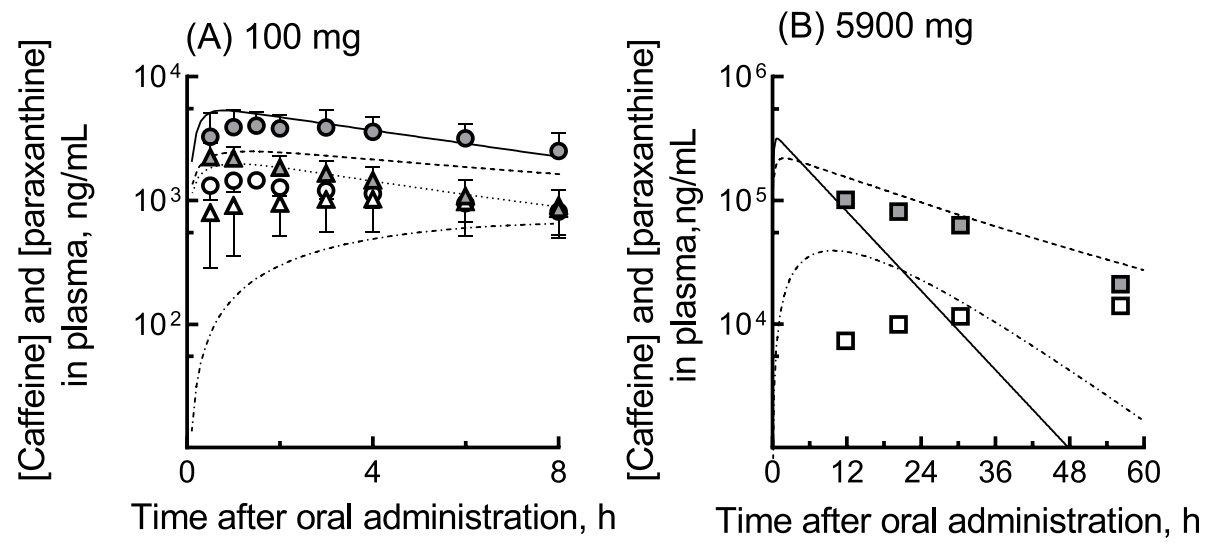

Fig. 1 (A) Reported (plots) and estimated (lines) plasma concentrations of caffeine and paraxanthine in male volunteers administered single oral doses of $100 \mathrm{mg}$ caffeine, and (B) measured (plots) and estimated (lines) concentrations of caffeine and paraxanthine in a female patient who took an oral overdose of $5900 \mathrm{mg}$ caffeine. (A) Plasma concentrations of caffeine (closed symbols) and paraxanthine (open symbols) were taken from the literature (circles, from 4 Japanese volunteers [3]; triangles, from 30 Caucasian volunteers [4]). The plasma concentrations of caffeine (solid line) and paraxanthine (dash-dot line) estimated using the current simplified PBPK model and the estimated caffeine concentrations for virtual Japanese (dashed line) and Causation (dotted line) populations generated by the Simcyp simulator are also shown. (B) Measured plasma concentrations of caffeine (closed squares) and paraxanthine (open squares) in a patient who took a single oral caffeine overdose of $5900 \mathrm{mg}$. Solid and dashed lines are estimated plasma caffeine concentrations generated by the current simplified PBPK model and by the Simcyp simulator, respectively. The dash-dot line shows the PBPK-modeled paraxanthine concentrations

concentrations $\geq 10 \mathrm{ng} / \mathrm{mL}$ and detectable at concentrations $\geq 1.0 \mathrm{ng} / \mathrm{mL}$. Inter- and intra-assay variability for caffeine and paraxanthine determinations were within $15 \%$ of coefficients of variation. Authentic caffeine and paraxanthine were purchased from Fujifilm Wako Pure Chemicals, Osaka, Japan, and ${ }^{13} \mathrm{C}$-caffeine was obtained from Sigma-Aldrich, St. Louis, MO, USA. Plasma concentrations of quetiapine, trazodone, and risperidone, which were ingested simultaneously with the caffeine, were also determined as described previously [18].

Figure 1B shows the measured plasma concentrations of caffeine and its primary metabolite paraxanthine along with the PBPK-modeled concentration profiles of the drug, which was self-administered in a single oral overdose in the current case. The plasma concentrations of caffeine and paraxanthine were 100 and $7.3 \mu \mathrm{g} / \mathrm{mL}, 81$ and $9.9 \mu \mathrm{g} / \mathrm{mL}, 63$ and $12 \mu \mathrm{g} / \mathrm{mL}$, and 21 and $14 \mu \mathrm{g} / \mathrm{mL}$ at $12,20,30$, and $56 \mathrm{~h}$, respectively, after an oral overdose of $5900 \mathrm{mg}$.

Measurements of the simultaneously co-administered medicines revealed a plasma quetiapine level of $10 \mathrm{ng} /$ $\mathrm{mL} 12 \mathrm{~h}$ after administration, with detectable $(\geq 0.10 \mathrm{ng} /$ $\mathrm{mL}$ ) traces at $20-56 \mathrm{~h}$, possibly after an approximately normal dose of $25 \mathrm{mg}$ quetiapine [19]. Plasma trazodone levels of 50 and $17 \mathrm{ng} / \mathrm{mL}$ at 12 and $20 \mathrm{~h}$, respectively, after administration were also determined, with detectable $(\geq 0.10 \mathrm{ng} / \mathrm{mL})$ traces at 30 and $56 \mathrm{~h}$, possibly after an approximately normal dose of $50 \mathrm{mg}$ trazodone [20], as judged by our previous simulation system $[18,21]$. Similarly, detectable traces of risperidone $(\sim 0.10 \mathrm{ng} / \mathrm{mL})$ were found in plasma, but the concentration could not be determined (data not shown). A rapid urine test for detecting benzodiazepines (Triage DOA, Sysmex, Kobe, Japan) showed a marginally false positive level in this case.

We also report the plasma concentration profiles for caffeine and paraxanthine generated by PBPK modeling. Based on the reported human blood concentrations of healthy volunteers who were orally treated with a normal therapeutic dose $[3,4]$, a simplified PBPK caffeine model consisting of gut, liver, kidney, and central compartments was set up as described previously [17, 18, $22]$. The initial values for the fraction absorbed $\times$ intestinal availability $\left(F_{a} \cdot F_{g}\right)$ and hepatic clearance $\left(C L_{\mathrm{h}}\right)$ were estimated from the elimination constants in empirical one-compartment models. The absorption rate constant $\left(k_{\mathrm{a}}\right)$, volume of the systemic circulation $\left(V_{1}\right)$, and hepatic intrinsic clearance $\left(C L_{\mathrm{h}, \text { int }}\right)$ values with standard deviations (as parameters for the PBPK models) were determined by fitting using nonlinear regression analyses; these final parameters are shown in Table 2. The resulting system of differential equations was solved to obtain the concentrations of caffeine and its metabolite (indicated with subscript $m$ ) for the overdose patient in the current study:

$$
\begin{aligned}
& \frac{d X_{g}}{d t}=-k_{a} \cdot X_{g} \text { when at } t=0, X_{g}(0) \\
& =F \mathrm{a} \cdot F \mathrm{~g} \cdot \text { dose } \\
& \begin{aligned}
V_{h} \frac{d C_{h}}{d t}= & k_{a} \cdot X_{g}-\frac{Q_{h} \cdot C_{h} \cdot R_{b}}{K_{p, h}}-C L_{h, \text { int }} \cdot \frac{C_{h}}{K_{p, h}} \cdot f_{u, p} \\
& \quad+Q_{h} \cdot C_{b}
\end{aligned}
\end{aligned}
$$


Table 2 Physiological, experimental, and final calculated parameters for PBPK models of caffeine and paraxanthine established in this study

\begin{tabular}{|c|c|c|}
\hline Parameter & Caffeine & Paraxanthine \\
\hline \multicolumn{3}{|l|}{ Model input parameters } \\
\hline Molecular weight & 194 & 180 \\
\hline Octanol-water partition coefficient & -0.04 & -0.279 \\
\hline Plasma unbound fraction & 0.758 & 0.798 \\
\hline Blood-plasma concentration ratio & 0.822 & 0.798 \\
\hline Liver-plasma concentration ratio & 0.681 & 0.689 \\
\hline Fraction absorbed $\times$ intestinal availability & 1 & - \\
\hline Absorption rate constant, $1 / \mathrm{h}$ & $4.94 \pm 0.15^{\mathrm{a}}$ & - \\
\hline Volume of systemic circulation, $\mathrm{L}$ & $18.8 \pm 0.1^{\mathrm{a}}$ & $74.5 \pm 0.1^{\mathrm{a}}$ \\
\hline Hepatic intrinsic clearance, $L / h$ & $2.70 \pm 0.05^{a}$ & $6.66 \pm 0.08^{a}$ \\
\hline Hepatic clearance, L/h & 2.00 & 5.04 \\
\hline Renal clearance, L/h & 0.06 & 0.15 \\
\hline \multicolumn{3}{|l|}{ Estimated values ${ }^{b}$} \\
\hline $\mathrm{C}_{\max }$ in plasma, $\mathrm{ng} / \mathrm{mL}$ & $5340(1.3)^{c}$ & $649(0.45)^{c}$ \\
\hline AUC in plasma, $\mathrm{ng} \mathrm{h} / \mathrm{mL}$ & $29,300(1.1)^{c}$ & $3440(0.40)^{c}$ \\
\hline \multicolumn{3}{|l|}{ Reported levels ${ }^{d}$} \\
\hline $\mathrm{C}_{\max }$ in plasma, $\mathrm{ng} / \mathrm{mL}$ & 4020 & 1450 \\
\hline AUC in plasma, $\mathrm{ng} \mathrm{h/mL}$ & 26,600 & 8680 \\
\hline Bioavailability & 1 & - \\
\hline Urinary excretion of unchanged drug & 0.03 & - \\
\hline
\end{tabular}

The plasma unbound fraction, octanol-water partition coefficient, blood-to-plasma concentration ratio, and liver-to-plasma concentration ratio of caffeine and paraxanthine were estimated using in silico tools [23]

aData are means \pm standard deviations by fitting to measured concentrations

${ }^{b}$ Values estimated by the simplified PBPK models for a normal single oral dose of $100 \mathrm{mg}$ caffeine

'Values in parentheses are ratios to the reported/observed values taken from the literature [3]

${ }^{\mathrm{d}}$ Reported values for four Japanese male volunteers administered single oral doses of $100 \mathrm{mg}$ caffeine [3]

$$
\begin{aligned}
V_{1} \frac{d C_{b}}{d t}=- & \left(Q_{h}+Q_{r}\right) \cdot C_{b}+\frac{Q_{h} \cdot C_{h} \cdot R_{b}}{K_{p, h}} \\
+ & \frac{Q_{r} \cdot C_{r} \cdot R_{b}}{K_{p, r}} \\
V_{r} \frac{d C_{r}}{d t}=Q_{r} \cdot C_{b}-\frac{Q_{r} \cdot C_{r} \cdot R_{b}}{K_{p, r}}-C L_{r} \cdot \frac{C_{r}}{K_{p, r}} \cdot f_{u, p} & \\
V_{h, m} \frac{d C_{h, m}}{d t}= & Q_{h} \cdot C_{b, m}-\frac{Q_{h} \cdot C_{h, m} \cdot R_{b, m}}{K_{p, h, m}}+C L_{h, i n t} \\
& \cdot \frac{C_{h}}{K_{p, h}} \cdot f_{u, p}-C L_{h, i n t, m} \cdot \frac{C_{h, m}}{K_{p, h, m}} \cdot f_{u, p, m} \\
V_{1, m} \frac{d C_{b, m}}{d t}= & -\left(Q_{h}+Q_{r}\right) \cdot C_{b, m}+\frac{Q_{h} \cdot C_{h, m} \cdot R_{b, m}}{K_{p, h, m}} \\
& +\frac{Q_{r} \cdot C_{r, m} \cdot R_{b, m}}{K_{p, r, m}} \\
V_{r, m} \frac{d C_{r, m}}{d t}= & Q_{r} \cdot C_{b, m}-\frac{Q_{r} \cdot C_{r, m} \cdot R_{b, m}}{K_{p, r, m}}-C L_{r, m} \\
& \cdot \frac{C_{r, m}}{K_{p, r, m}} \cdot f_{u, p, m}
\end{aligned}
$$

where $X_{\mathrm{g}}, C_{\mathrm{h}}, C_{\mathrm{r}}$, and $C_{\mathrm{b}}$ are the amount of compound in the gut compartment and the hepatic, renal, and blood substrate concentrations, respectively. $V_{h}$ and $V_{\mathrm{r}}$ are the liver $(1.5 \mathrm{~L})$ and kidney $(0.28 \mathrm{~L})$ volumes, and $Q_{\mathrm{h}} /$ $Q_{\mathrm{r}}$ are the blood flow rates of the systemic circulation to the hepatic/renal compartments $(96.6 \mathrm{~L} / \mathrm{h})$. A full PBPK modeling simulation of caffeine was also performed with caffeine-specific physicochemical parameters using the Simcyp simulator version 20 (Certara UK, Simcyp Division, Sheffield, UK) following the modified population parameters recently described [12].

\section{Discussion and conclusions}

The reported plasma concentrations of caffeine and its primary metabolite paraxanthine after single oral 100mg doses of caffeine in 4 healthy Japanese and 30 Caucasian volunteers are illustrated in Fig. 1A. The mean concentrations of caffeine in Japanese subjects appeared to be higher than those in Caucasians, whereas the levels of metabolite paraxanthine were similar in these two groups. In the current study, a simplified PBPK model for caffeine was set up based on these reported plasma 
concentrations of caffeine and paraxanthine in Japanese volunteers. Figure 1B shows the concentrations of caffeine and paraxanthine measured at 12, 20,30, and $56 \mathrm{~h}$ after the oral overdose of $5900 \mathrm{mg}$. The measured plasma concentrations of caffeine of around $100 \mu \mathrm{g} / \mathrm{mL}$ in the current case appeared not to have caused hepatic impairment, as judged by the clinical laboratory results shown in Table 1. Furthermore, lines of evidence based on the plasma levels of the medicines co-administered with the caffeine implied that the doses of lorazepam, quetiapine, risperidone, and trazodone were roughly equal to the normal dose in this case.

The observed terminal elimination half-life of caffeine of $27 \mathrm{~h}$ (calculated from the two data points on days 1 and 2 and $16 \mathrm{~h}$ on day 3 ) after the 5900-mg overdose was several times longer than the reported normal values of 2-12 h [1]. This finding implies nonlinearity of caffeine pharmacokinetics over a wide dose range as suggested [23], thereby affecting the accuracy of the values simulated by the simplified PBPK model in the present case. As a result, the observed primary metabolite paraxanthine concentrations in plasma in the current patient were much higher from day 3 than the levels predicted by the simplified PBPK model. Low serum potassium levels on days 1 and 2 (Table 1) may have been caused by the caffeine overdose. It has been reported that 22 cases of fatal overdosage that resulted from the oral administration of $5.3-52 \mathrm{~g}$ of caffeine [1]. A rapid treatment such as gastric lavage is generally proposed to be undertaken within $60 \mathrm{~min}$ of ingestion [24]. However, the patient underwent infusion with bicarbonate Ringer's solution and potassium chloride and was discharged on the third day of hospitalization.

The measured caffeine concentrations in the current overdose patient clearly indicated abnormal caffeine pharmacokinetics after taking a potentially lethal dose of caffeine. The apparent limitations of the current simplified PBPK model, which was set up based on reported plasma concentration curves for normal doses, resulted from the nonlinearity of caffeine pharmacokinetics over a wide range of drug doses; however, the in vitro-in vivo extrapolation system in the full Simcyp PBPK model was not adversely affected by this nonlinearity. These results illustrate the fact that simplified PBPK simulation systems can only be utilized appropriately if the upper dosage limit for dose-concentration linearity is known. Further model assessments and the accumulation of data and knowledge from additional overdose cases will be needed. In our previous report of overdoses of quetiapine and trazodone in combination [18], the plasma concentrations of these co-administered drugs were within their linear ranges, meaning that simplified PBPK simulation systems could be successfully applied. Such simplified PBPK models for predicting the amounts of drugs taken accidentally or intentionally can be used to facilitate the assessment of such emergently admitted cases.

In hospitals, a simulator based on simplified PBPK models may be a useful addition to the routine measurements of drug concentrations in blood. The present results, based on drug monitoring data and pharmacokinetic predictions by prepared systems in advance $[25,26]$, could serve as a useful guide when assessing and setting the treatments for overdose patients.

\section{Abbreviation}

PBPK: Physiologically based pharmacokinetic

\section{Acknowledgments}

The authors greatly thank Yusuke Kamiya, Norie Murayama, Shiori Hina, Wataru Kobari, and Masaya Fujii for their technical support, and David Smallbones for copyediting a draft of this article.

\section{Authors' contributions}

$\mathrm{KA}, \mathrm{SB}$, and MT monitored the patients and carried out the acquisition of patient data. KA, JT, MS, and HY conceived the pharmacokinetic study and drafted the manuscript. SB, MT, and TF analyzed the patient medical data and helped to draft the manuscript. All authors have read and approved the final manuscript.

\section{Funding}

This work was supported in part by the METI Artificial Intelligence-based Substance Hazard Integrated Prediction System Project, Japan.

\section{Availability of data and materials}

All data generated or analyzed during this study are included in this published article and are also available from the corresponding author on reasonable request.

\section{Declarations}

Ethics approval and consent to participate

This study was approved by the Ethics Committee of Kyoto Medical Center.

\section{Consent for publication}

Informed consent was obtained from the patient.

\section{Competing interests}

The authors declare that they have no competing interests.

\section{Author details}

'Laboratory of Drug Metabolism and Pharmacokinetics, Showa

Pharmaceutical University, 3-3165 Higashi-tamagawa Gakuen, Machida, Tokyo 194-8543, Japan. ${ }^{2}$ Kyoto Medical Center, Fukakusa Mukaihata-cho, Fushimi-ku, Kyoto 612-8555, Japan. ${ }^{3}$ Himeji Medical Center, Himeji, Hyogo 670-8520, Japan.

Received: 19 May 2021 Accepted: 10 August 2021

Published online: 04 October 2021

\section{References}

1. Baselt RC. Caffeine. Disposition of toxic drugs and chemicals in man. 12th ed. Seal Beach, California: Biomedical Publications; 2020. p. 315-8.

2. Sakai $C$, Iwano $S$, Yamazaki $Y$, Ando $Y$, Nakane $F$, Kouno $M$, et al. Species differences in the pharmacokinetic parameters of cytochrome P450 probe substrates between experimental animals, such as mice, rats, dogs, monkeys, and microminipigs, and humans. J Drug Metab Toxicol. 2014;5: 173.

3. Tanaka S, Uchida S, Inui N, Takeuchi K, Watanabe H, Namiki N. Simultaneous LC-MS/MS analysis of the plasma concentrations of a cocktail of 5 cytochrome P450 substrate drugs and their metabolites. Biol Pharm Bull. 2014;37(1):18-25. https://doi.org/10.1248/bpb.b13-00401.

4. Turpault S, Brian W, Van HR, Santoni A, Poitiers F, Donazzolo Y, et al. Pharmacokinetic assessment of a five-probe cocktail for CYPs 1A2, 2C9, 
2C19, 2D6 and 3A. Br J Clin Pharmacol. 2009;68(6):928-35. https://doi.org/1 0.1111/j.1365-2125.2009.03548.x.

5. Jabbar SB, Hanly MG. Fatal caffeine overdose: a case report and review of literature. Am J Forensic Med Pathol. 2013;34(4):321-4. https://doi.org/10.1 097/PAF.00000000000000058.

6. Kohl BA, Kaur K, Dincher N, Schumann J, Carachilo T, Komurek C. Acute intentional caffeine overdose treated preemptively with hemodialysis. Am J Emerg Med. 2020;38:692 e1-3.

7. Muraro L, Longo L, Geraldini F, Bortot A, Paoli A, Boscolo A. Intralipid in acute caffeine intoxication: a case report. Anesth. 2016;30:895-9.

8. Yasuda S, Hisamura M, Hirano T, Kukihara Y, Kodama K, Konishi K, et al. Caffeine poisoning successfully treated by venoarterial extracorporeal membrane oxygenation and emergency hemodialysis. Acute Med Surg. 2021;8:e627.

9. Kitano T, Okajima M, Sato K, Noda T, Taniguchi T. Suicidal attempt with caffeine overdose treated with dexmedetomidine: a case report. J Med Case Rep. 2021;15(1):11. https://doi.org/10.1186/s13256-020-02611-6.

10. Nojima T, Naito H, Kosaki Y, Osako T, Tanaka K, Murata A, et al. Caffeine intoxication in pregnancy; a case report. Arch Acad Emerg Med. 2019;7:e67.

11. Jamei M, Marciniak S, Feng K, Barnett A, Tucker G, Rostami-Hodjegan A. The Simcyp population-based ADME simulator. Expert Opin Drug Metab Toxicol. 2009;5(2):211-23. https://doi.org/10.1517/17425250802691074.

12. Matsuzaki T, Scotcher D, Darwich AS, Galetin A, Rostami-Hodjegan A. Towards further verification of physiologically-based kidney models: predictability of the effects of urine-flow and urine-pH on renal clearance. J Pharmacol Exp Ther. 2019;368(2):157-68. https://doi.org/10.1124/jpet.118.2 51413.

13. Ota M, Shimizu M, Kamiya Y, Emoto C, Fukuda T, Yamazaki H. Adult and infant pharmacokinetic profiling of dihydrocodeine using physiologically based pharmacokinetic modeling. Biopharm Drug Dispos. 2019;40(9):350-7. https://doi.org/10.1002/bdd.2209.

14. Notsu Y, Shimizu M, Sasaki T, Nakano A, Ota M, Yoshida S, et al. Simple pharmacokinetic models accounting for drug monitoring results of atomoxetine and its 4-hydroxylated metabolites in Japanese pediatric patients genotyped for cytochrome P450 2D6. Drug Metab Pharmacokinet. 2020;35(2):191-200. https://doi.org/10.1016/j.dmpk.2019.08.005.

15. Emoto C, Shimizu M, Tanaka T, Yamazaki H. Feasibility of physiologically based pharmacokinetic simulations for assessing pediatric patients after accidental drug ingestion: a case study of a 1.4-year-old girl who ingested alprazolam. Drug Metab Pharmacokinet. 2021;39:100394. https://doi.org/10.1 016/j.dmpk.2021.100394

16. Kamiya Y, Otsuka S, Miura T, Takaku H, Yamada R, Nakazato M, et al. Plasma and hepatic concentrations of chemicals after virtual oral administrations extrapolated using rat plasma data and simple physiologically based pharmacokinetic models. Chem Res Toxicol. 2019;32(1):211-8. https://doi. org/10.1021/acs.chemrestox.8b00307.

17. Adachi K, Tuchiya J, Beppu S, Nishiyama K, Shimizu M, Yamazaki H. Pharmacokinetics of anticoagulant edoxaban in overdose in a Japanese patient transported to hospital. J Pharm Health Care Sci. 2020;6(1):20. https://doi.org/10.1186/s40780-020-00176-6.

18. Adachi K, Beppu S, Nishiyama K, Shimizu M, Yamazaki H. Pharmacokinetics of duloxetine self-administered in overdose with quetiapine and other antipsychotic drugs in a Japanese patient admitted to hospital. J Pharm Health Care Sci. 2021;7(1):6. https://doi.org/10.1186/s40780-021-00189-9.

19. Grimm SW, Richtand NM, Winter HR, Stams KR, Reele SB. Effects of cytochrome P450 3A modulators ketoconazole and carbamazepine on quetiapine pharmacokinetics. Br J Clin Pharmacol. 2006;61(1):58-69. https:// doi.org/10.1111/j.1365-2125.2005.02507.x.

20. Farkas D, Volak LP, Harmatz JS, von Moltke LL, Court MH, Greenblatt DJ. Short-term clarithromycin administration impairs clearance and enhances pharmacodynamic effects of trazodone but not of zolpidem. Clin Pharmacol Ther. 2009;85(6):644-50. https://doi.org/10.1038/clpt.2008.293.

21. Okubo M, Morita S, Murayama N, Akimoto Y, Goto A, Yamazaki H. Individual differences in in vitro and in vivo metabolic clearances of antipsychotic risperidone from Japanese subjects genotyped for cytochrome P450 2D6 and 3A5. Hum Psychopharmacol. 2016;31(2):93-102. https://doi.org/10.1002/ hup.2516.

22. Kamiya Y, Otsuka S, Miura T, Yoshizawa M, Nakano A, Iwasaki M, et al. Physiologically based pharmacokinetic models predicting renal and hepatic concentrations of industrial chemicals after virtual oral doses in rats. Chem
Res Toxicol. 2020;33(7):1736-51. https://doi.org/10.1021/acs.chemrestox. 0c00009.

23. Denaro CP, Brown CR, Wilson M, Jacob P 3rd, Benowitz NL. Dosedependency of caffeine metabolism with repeated dosing. Clin Pharmacol Ther. 1990;48(3):277-85. https://doi.org/10.1038/clpt.1990.150.

24. Vale JA. Position statement: gastric lavage. American Academy of clinical toxicology; European Association of Poisons Centres and Clinical Toxicologists. J Toxicol Clin Toxicol. 1997;35(7):711-9. https://doi.org/10.31 09/15563659709162568.

25. Adachi K, Beppu S, Terashima M, Kobari W, Shimizu M, Yamazaki H. Pharmacokinetic modeling of over-the-counter drug diphenhydramine selfadministered in overdoses in Japanese patients admitted to hospital. J Pharm Health Care Sci. 2021, in press. https://doi.org/10.1186/s40780-02100215-w.

26. Adachi K, Sugitani Y, Unita R, Yoshida K, Beppu S, Terashima M, Fuji M, Shimizu M, Yamazakiet H. Pharmacokinetics of loxoprofen in a selfadministered overdose in a Japanese patient admitted to hospital. J Pharm Health Care Sci. 2021. in press. https://doi.org/10.1186/s40780-021-00216-9.

\section{Publisher's Note}

Springer Nature remains neutral with regard to jurisdictional claims in published maps and institutional affiliations.
Ready to submit your research? Choose BMC and benefit from:

- fast, convenient online submission

- thorough peer review by experienced researchers in your field

- rapid publication on acceptance

- support for research data, including large and complex data types

- gold Open Access which fosters wider collaboration and increased citations

- maximum visibility for your research: over $100 \mathrm{M}$ website views per year

At BMC, research is always in progress.

Learn more biomedcentral.com/submissions 